\title{
Teachers' Beliefs about Mathematics and Instructional Practices
}

\author{
Basanta Raj Lamichhane ${ }^{1}$
}

\begin{abstract}
This paper deals with the teachers' beliefs about mathematics and relations with their instructional practices based on contemporary literatures and my own experiences. Beliefs have generally been perceived through the personal experiences and interactions with immediate environment and setting. Philosophical beliefs have in the central positions, which are not easily liable to change whereas curricular and pedagogical beliefs seem to be secondary and remain fluids. Two general trends have been observed regarding the relation of teachers' beliefs about mathematics and instructional practices: conventional pedagogical practices associated with absolutist philosophical, and technically informed curricular beliefs. However, the contemporary/constructivist pedagogical practices are related with fallibilist philosophical beliefs and practical, informed and emancipatory oriented curricular beliefs.
\end{abstract}

Keywords: Mathematical beliefs, philosophy, curriculum, pedagogy and instructional practices.

\section{Setting the Scene}

Mathematics has a crucial role for the development of the natural sciences, information and communication technology, space sciences, and other human disciplines as well. Mathematics has a power to express the physical world in simple, systematic and consistent ways so what many students, teachers and researchers valued mathematics (Ernest, 2008). In spite of having the foundational role for developing other human disciplines and enriching the problem solving, describing, interpreting, and decision making skills in the real world situation, many practitioners perceive mathematics as one of the difficult subjects and do not succeed sufficiently as per public expectation (Trends in International Mathematics and Science Study [TIMSS], 2011; Programme for International Student Assessment [PISA], 2012). Why such condition arises is one of the challenging questions for the mathematics teachers, teacher educators and researchers. It opens an avenue of my inquiry. In my opinion, our school and university mathematics curricula and activities focus on only one aspect of cognitive development and often overlook other aspects of teaching learning activities; one of such hidden variable is belief (Leder, Pehkonen, \&Törner, 2003).

A recent research on teachers' beliefs explores a significant positive relationship among teachers' beliefs, practices and students' problem solving achievement (Polly et al., 2013). Classroom activities of teachers are guided by their prejudiced assumptions. They do not simply perform as robot. Being a human being, they have their own feelings, emotions and passions about their environments. These attributes appear in their classroom instructional practices. Handal and Herrington (2003) argued that teacher belief plays a

1 Lecturer, Dept. of Mathematics, Saptagandaki Multiple Campus 
vital role in the nature of classroom instructions and implementation of mathematics curricular reform. For enhancing the quality of mathematics teaching and learning, we should understand the ideas held by the teachers and how these ideas or beliefs have reflected in their instructional practices (Boz, 2008).

According to Thompson (1992), the efforts to improve the quality of mathematics instruction should not result significant outcomes, if the related personnel and authorities are not able to recognize a role that the teachers' beliefs might play in shaping their behaviour. Teachers' behaviour is primarily determined by their belief system rather than by their own knowledge. Experience and prior knowledge are also important, but beliefs act as the driving forces in shaping the structure and content of their practices in the classroom (Wilson \& Cooney, 2003). Similarly, Ernest (1991) claimed that teachers' knowledge of mathematics is important but not account for every difference observed in the classroom. These perspectives elucidate the views that only mathematics content knowledge is not sufficient for a betterment of mathematics education practices. So why do many researchers focus on teachers' beliefs to account for positive changes in mathematics teaching and learning practices? In this connection, the main purpose of the paper is to explore the mathematical beliefs of teachers and how these beliefs reflect on their instructional practices. To furnish the task I briefly review the latest literatures that have devoted to investigate teachers' beliefs and their instructional practices in mathematics and then provide a general description of the constructs. For this, I have attempted to provide some basic concepts of beliefs and its relation with practices. Then I articulate the teachers' beliefs about mathematics, captured under philosophical, curricular and pedagogical issues and try to tie with instructional practices.

\section{Conceptualizing the Beliefs about Mathematics}

Belief is largely individual construct. It describes one's personal notions, perceptions, and conceptions of truth and reality (McLeod\&McLeod, 2003). It is highly subjective because every individual perceives his /her environment according as his/her senses, and one's mental construct through which they describe their environment from their own perspectives. In this process s/he makes his/her individual meaning about phenomenon under consideration generally termed as belief. So knowledge and beliefs are different in terms of their level of precision. Knowledge is a collection of cognitive concepts or ideas that have been accepted and validated by wider community through their experiences. Whereas, beliefs are notions about an idea or concept regarding particular events, behaviour, objects or phenomenon that held individually so that its validity and legitimacy are free from external judgments.

Thus beliefs are psychological understanding, premises, or propositions about the world that are seemed to be true and constructed during different actions and interactions with environments. That is, belief is not per-conceived mental conceptions rather it is a product of human activities. So it has incorporated both cognitive and affective aspect of learning. Wilson and Cooney (2003) mentioned that beliefs are usually seen as the constructs that have cognitive component but it is weaker condition than knowing. Similarly, Goldin (2003) argued that "beliefs are multiply-encoded cognitive/affective configurations to which the 
holder attributes some kind of truth value"(p.59). Thus, I understood that beliefs evolve during educational, social, cultural and professional experiences and takes different forms and remain fluids.

\section{Mathematical Beliefs and Instructional Practices}

Many researchers (Thomson, 1992; Beswick, 2007; Stipek, et al.2001) showed that there is a strong relationship between teachers' mathematical beliefs and instructional practices. Beswick (2007) identified nine crucial beliefs of teachers emerged from their classroom observations, interviews with teachers and students survey. Heclassified these beliefs into three categories: belief about nature of mathematics, belief about mathematics learning and belief about the role of teachers. Similarly, Eynde, Corte, and Verschaffel (2003) summarized the beliefs about mathematics under four different categories: belief about the natures of mathematics and mathematical learning, belief about the self in the context of mathematics learning and problem solving, beliefs about the mathematics teaching and epistemological beliefs. Moreover, Ernest (1998) described the key belief components: nature of mathematics, nature of mathematics teaching, and process of mathematics learning that affect the mathematics teaching leaching activities. Based on these literatures, I would try to capture the notion of beliefs about mathematics and corresponding instructional activities under philosophical, curricular and pedagogical aspects.

\section{Philosophical Beliefs and Practices}

Philosophy is a worldview or belief systems that guides our thinking, reasoning and thus directs our actions (Willis, 2007). Philosophical standpoint of the teachers and students about the nature of mathematics reflect on their mathematical teaching learning activities within and outside schools. I have observed two school of thoughts; absolutism and fallibilism (Ernest, 1991) in mathematics that might affect the overall practices of mathematics. Absolutism regards mathematics as a certain, unchangeable, and rigid body of knowledge free from socio-cultural activities. Whereas fallibilism regards mathematics as an uncertain, corrigible and product of different cultural activities (Ernest, 1998). These two contrasting views steer our educational activities as well.

Those who believe on absolutist thoughts their activities lean to achieve objective knowledge of mathematics being exist 'out there' in the universe through transmissionist approach. Stipek, et al. (2001) argued that many teachers believe mathematics as a tool or procedure to solve computational problems and their practices mainly directed toward getting a correct solution. They also explored the consistent associations between beliefs and practices. Thus, I came to realize that those who believe on realist ontology and objective epistemology of mathematical objects and knowledge largely tend to follow behaviourist instructional practices.

However, those who believe on fallibilist nature of mathematics their activities tilt towards a constructionist approach and focus on the subjective nature of mathematics. Beswick (2007) reveled that those teachers who believed on mathematics as a subjects of connecting ideas, sense-making and conceptual understanding 
then they viewed learning as unpredictable and all students can learn mathematics. He further argued that those teachers who viewed mathematic as a subject of interpretive, their roles have to facilitate learners, guide students' construction of mathematical knowledge and induct students into widely accepted ways of thinking, creating, imagining and communicating mathematics. In this connection, I realize that those teachers who believe on relativist ontology and inter/subjective epistemology of mathematical objects and knowledge, they largely tend to adopt the constructivist instructional practices. These philosophical beliefs explicitly or implicitly contribute to curricular and pedagogical beliefs.

\section{Curricular Beliefs and Practices}

Curricular belief is the most debatable issue in teaching learning activities in schools and universities mathematics. Generally, the curricular beliefs can be captured under three categories: technical informed, practically informed and emancipatory oriented (Grundy, 1987) that directly associated with Habermasian knowledge constitutive interests (Habermas 1972).

Those who believe on technical interests viewed curriculum as subject matters or contents, discrete tasks, planned activities and cultural reproduction (Schubert, 1986). It focuses on structural orientation (Luitel, 2009) in which curriculum regards as an object and a finish product. Such beliefs regard curriculum as final written document should not provide the flourishing ground for creative, reflective, imaginative and critical thinking (Grundy, 1987). These attributes are essentials for the overall development of the individuals for their independent living. If the teachers held the technical informed curriculum beliefs, then their work will be limited in the level of distributing/transmitting/dispensing (Grundy, 1987) the previously chosen packaged knowledge, checking pre-set tests and perform general filing duties. Technically informed curricular beliefs lead to the curricula discourse in the means and ends dualism in which students regard as means and goals and objectives as the ends. It signifies that it ignores the learners as cognizing being and learning as becoming. Design views, industrial model and curriculum as product are the major metaphorical images of curriculum that gave the birth of one size fit all pedagogical approaches (Friere, 1993).

Likewise, those who believe on practical interests regard curriculum as experiences or currere(Schubert, 1986). It focuses on historical-hermeneutic and interactional (Grundy, 1987) approach of curriculum development in which teachers and students experiences are valued. Lloyd (2003) argued that when teachers believe on practical interests, it leads to increase teachers' ability to handle a classroom so that teachers incorporate and value the students' learning ability in which both of them are engaged in mathematical conceptual understanding, meaning and sense-making process rather than algorithmic computation within and outside of the classroom activities. From this discussion, I realize that if the teachers believe on the practically informed curriculum, then they focus on humanizing pedagogy so that classroom becomes a learning culture.

In contrast to these two views, teachers' beliefs on emancipatory oriented curriculum not only focus on the understanding of the reality but also on how to change or transform the teaching learning activities so that 
learners become autonomous and independent critical thinkers. Those who held emancipatory curriculum beliefs, their instructional activities are headed towards for developing a critical thinking of learners so that they explore the factors that make suppression (Taylor \& Williams, 1992). Thus, the emancipatory beliefs of teachers allow students to raise the issues of social justice, inequality, and discrimination. Teachers generally tend to use problem posing pedagogical approaches in which both of them simultaneously engage teaching learning activities. They aim to develop the critical consciousness among the participants. So they try to create an ideal speech situation in classroom in which every student gets full opportunity to participate in classroom discourses without any sort of coercion, questions each other taken for granted assumptions and develop unimpaired self-representation so that classroom becomes living cultural (Taylor \& Williams, 1992).Such classroom practices help to promote the deep democratic practices within and outside school (Tutak, Bondy\& Adams, 2011).Thus, I make a sense that these three types of curriculum beliefs: technical, practical and emancipatory directed towards transmissionist/conventional, humanizing and constructivist/ transformative approaches teaching learning activities respectively. The role of teacher within these three domains of beliefs in classroom activities appears to be autocratic, negotiators, and coconstructor or facilitator.

\section{Pedagogical Beliefs and Practices}

Teachers' values, beliefs, attitudes and emotions are some of the implicit factors that might govern the individual thinking and action. Recent research studies (Lane, Stynes, \&O’Donghue, 2014, Kloosterman, 2003) highlighted the role of these forces in teaching learning and motivational activities of students and teachers themselves. Teacher pedagogical belief is the conception about teaching mathematics. It incorporates teachers' roles, actions, and classroom activities. Ernest (1989) explored three different roles and associated outcomes of instruction. According to him those who believe on instruction focuses on mastery of certain skills and algorithms with correct answer whereas those who confined themselves as explainer give emphasis on understating with unified knowledge. However, those who act as facilitators adopt problem posing strategies. In a similar vein, educators (Lerman, 2003; Cobb \& Steffe, 2011) identified two major beliefs of a teacher: instructive and constructive, regarding their pedagogical practices.

Stipek et al. (2001) find the positive association between instructive beliefs and traditional transmissionist practices. They further argued that teachers with instructive beliefs are not concerned about the students conceptual understudying and meaning making process, rather they focus on algorithm and speed in the classroom. Students are expected to absorb and reproduce mathematical facts, concepts, and rules. These activities are largely guided by behaviourist learning theories. According to behaviourist approaches, learning or knowing emerges through the process of sensationalism, reductionism, asssociationism, and mechanism (Bower \&Hilgard, 1986) and ignore a role of human cognition. Highlighting the characteristics of behaviourism in formal mathematics classes, Taylor, Luitel, Desautels, and Tobin (2007) argue that there is no opportunity to students to share their true felling, lived realities and everyday life-worlds and so classroom become a place where teachers tell many lies to students because students would not be able 
to reject their voices as supposed to be legitimatize and authentic. I realize that such classroom practices further help to elevate or transmit the negative beliefs, attitudes, and images of mathematics to their students and finally may lead to avoidance of mathematics.

In contrast to this view, those teachers who believe on constructivist approach of teaching and learning mathematics focus on active engagement of learners in learning process rather than passive receiver of knowledge(Cook \& Cook, 2005). Constructivist teachers are those who always devote to create favourable learning environment in which students get full opportunity to construct their mathematical ideas in their own ways. Teacher facilitates students to construct new mathematical knowledge by providing scaffolding (Cook \& Cook, 2005) that are largely negotiated and mediated by larger communities of practitioners. In this perspective, cognition is not located purely within the individuals' mind; it has stretched across the whole body, cultural tools, socio-cultural activities and its context (Lerman, 1999). Furthermore, they believe that learning is not simply the accumulation of certain mathematical facts and knowledge into mental structures. It is largely an interpretive and narrative process (Burton, 1999) in which cultural tools, environments, beliefs, thoughts and actions are interweaving for generating and creating mathematical knowledge.

The constructive approach of mathematics teaching and learning is more empowering and inclusive than instructive approach. However, as I witnessed most of our teaching learning practices based on instructionist beliefs that focus on drills and practices. Mathematics classroom seems to be a place of imposing mathematical knowledge, skills and concepts to students without regarding their other backgrounds (ethnic and lingual backgrounds, socio-cultural aspects, prior knowledge, interests etc.). In this context, I realize that to transform conventional teaching learning activities into more authentic, empowering, and contextualized, deep rooted teacher beliefs/perceptions about mathematics need to be addressed.

\section{Conclusion}

Teachers' beliefs about mathematics are highly personalized construct that are emerged by their prior mathematical experiences, interactions with colleague, teachers, and their immediate environments. It is difficult to explore the personal feeling, beliefs, and attitudes explicitly because there is no window in heads through which we can see easily what happens in their mind, so the most appropriate ways of capturing such personal constructs are to observe their various actions, communications and interactions with their environments (Taylor \& Medina, 2011). That is, there are certain guiding or driving forces that govern our thinking and actions, which are not directly visible and measurable; one of such variable is belief.

From this discourse, I clearly capture two different trends of mathematical beliefs and their instructional practices. First one is that the teacher who held the absolutist beliefs about nature of mathematics tends to blend with technical interest of curriculum development that adopt a conventional/instructional pedagogical approach and thus their classroom practices become more transmissionist, autocratic, hierarchical, and disempowering. The other is that the teacher who hold fallibilist view of mathematics tries to incorporate 
practical and somehow emancipatory interest of curriculum development thus tends to incorporate humanizing and problem posing pedagogy in which students can get an opportunity to share their true felling without any sort of coercion so that classroom become the learning culture.

As I witness, as student, teacher, and teacher educator, whatever be the theoretical advancement has been taken place in the field of mathematics education, our teaching learning practices have not been able to cross the boundary of traditional transmissionist approaches. In my experiences, many students come to enroll in a university are likely to have negative attitudes, images, and beliefs towards mathematics but want to take mathematics as their optional subject because of the belief that it would secure their future jobs. Many of these negative conceptions and anxiety towards mathematics is the product of inappropriate teaching strategies, irrelevant curriculum, mistaken beliefs, and conceptions (Probert, 1983). Thus, I claim that to improve our teaching learning activities we should rethink from the very beginning of our educational practices particularly in mathematics education. In my opinion, we start from the nature of mathematics and should link with different civilizations and cultural activities, which give a true picture about mathematics and its historical- hermeneutic process of evolving. In my understating, if we incorporate the historicalhermeneutic approaches into our mathematics curriculum practices, then it explores the multidimensional nature of mathematical realities that relate classroom practices in broader social aspects. This may help to eliminate some of the misconceptions and myths about mathematics and help to improve our teaching learning activities.

\section{References}

Beswick, K. (2007). Teachers' beliefs that matter in secondary mathematics classrooms. Educational Studies in Mathematics, 65, 95-120.

Bower, G. H. \&Hilgard, E. R. (1986). Theories of Learning (5 $5^{\text {th }}$ d.). New Delhi: Prentice- Hall of India Private Limited.

Boz, N. (2008). Turkish pre-service mathematics teachers' beliefs about mathematics teaching. Australian Journal of Teacher Education, 33 (5), 66-80.

Burton, L. (1999). The implications of a narrative approach to the learning of mathematics. In L. Burton (Ed.), Learning mathematics: From hierarchies to networks. New York, NY: Falmer

Cobb, P. \&Steffe, L. P. (2011). The constructivist researcher as teacher and model Builder. In E. Yackel et al. (Eds.). A Journey in Mathematics Education Research. London and New York: Springer Science+Business Media B.V.

Cook, J. L., \& Cook, G. (2005). Child development: Principles and perspectives. Boston, MA: Pearson.

Ernest, P. (1989). The impact of beliefs on the teaching of mathematics. In P. Ernest (Ed.), Mathematics Teaching: The state of art. New York: Falmer.

Ernest, P. (1991). The philosophy of mathematics education. London: Falmer Press.

Ernest, P. (1998). Social constructivism as a philosophy of mathematics. USA: State University of New York Press. 
Ernest, P. (2008). Epistemology plus values equals classroom image of mathematics. Philosophy of Mathematics Education Journal, 23, 1-12.

Eynde, P. O., Corte. E.,\&Verschaffel, L. (2003). Framing students' mathematics-related beliefs. A quest for conceptual clarity and a comprehensive categorization. In G. C. Leder, E. Pehkonen, \& G. Törner (Eds.). Beliefs: A hidden variable in mathematics education? Dordrecht: Kluwer Academic Publishers.

Freire, P. (1993). Pedagogy of the oppressed. NY: Continuum.

Goldin, G. A. (2003). Affect, meta-affect, and mathematical belief structures. In G. C. Leder, E. Pehkonen, \&G. Törner (Eds.). Beliefs: A hidden variable in mathematics education? Dordrecht: Kluwer Academic Publishers.

Grundy, S. (1987). Curriculum: Product or praxis. London: The Flamer Press.

Habermas, J. (1972). Knowledge and human interests (Jeremy, J. S. Trans.). Boston: Beacon Press.

Handal, B. \& Herrington, A. (2003). Mathematics teachers' beliefs and curriculum reform. Mathematics Education Research Journal, 15 (1), 59-69.

Kloosterman, P. (2003). Beliefs about mathematics and mathematics learning in the secondary school: Measurement and implication for motivation. In G. C. Leder, E. Pehkonen, \&G. Törner (Eds.). Beliefs: A hidden variable in mathematics education? Dordrecht: Kluwer Academic Publishers.

Lane, C., Stynes, M., \&O'Donghue, J. (2014). The image of mathematics held by Irish post-primary students. International Journal of Mathematical Education in Science and Technology, 45(6), 879-891.

Leder, G. C., Pehkonen, E., \& Törner, G. (2003) (Eds.). Beliefs: A hidden variable in mathematics education? Dordrecht: Kluwer Academic Publishers.

Lerman, S. (1999). Culturally situated knowledge and the problem of transfer in the learning of mathematics. In L. Burton (Ed.). Learning mathematics: From hierarchies to networks. New York, NY: Falmer.

Lerman, S. (2003). Situating research on mathematics teachers' beliefs and on change. In G. C. Leder, E. Pehkonen, \& G. Törner(Eds.). Beliefs: A hidden variable in mathematics education? Dordrecht: Kluwer Academic Publishers.

Lloyd, G. M. (2003). Mathematics teachers' beliefs and Experiences with innovative curriculum Materials. The role of curriculum in teacher development. In G. C. Leder, E. Pehkonen, \& G. Törner (Eds.). Beliefs: A hidden variable in mathematics education? Dordrecht: Kluwer Academic Publishers.

Luitel, B.C. (2009) Culture, Worldview and Transformative Philosophy of Mathematics Education in Nepal: A Cultural-Philosophical Inquiry. Doctoral Dissertation, Curtin University of Technology.

Polly, D. et al. (2013). The association between teachers' beliefs, enacted practices, and student learning in mathematics. The Mathematics Educator, 22 (2), 11-30.

Probert, B. S. (1983). A multimodal group intervention strategy in mathematics anxiety/ avoidance. (Unpublished Doctoral Dissertation), Graduate Council, University of Florida.

Schubert, W. H. (1986). Curriculum: Perspective, paradigm and possibility. New York: Macmillan.

Stipek, et al. (2001). Teachers' beliefs and practices related to mathematics Instruction. Teaching and Teacher Education, 17, 213-226. 
Taylor, P.C. \& Medina, M. (2011). Educational research paradigms: From positivism to pluralism. College Research Journal, 1(1), 1-16. Assumption College of Nabunturan, Philippines.

Taylor, P.C. \& Williams, M. C. (1992). Discourse towards balanced rationality in the high school mathematics classroom: Ideas from Habermas' critical theory. A paper presented at the ' sociological and anthropological perspectives' working subgroup of Seventh international congress of mathematic education (ICME-7), 17-23 August 1992 Quebec.

Taylor, P.C., Luitel, B. C; De'sautels, J. \& Tobin, K. (2007). Forum: Contextualism and/or decontextualism, painting rich cultural pictures, and ethics of co-authorship; Cultural study of Science Education. 2, $621-655$.

Thompson, A. G. (1992). Teachers' beliefs and conceptions: A synthesis of the research. In D. A. Grouws (Ed.). Handbook of research on mathematics teaching and learning: A project of the National Council of Teachers of Mathematics. New York, NY: Macmillan.

Trends in International Mathematics and Science Study (2011). International mathematics report: Findings from IEA's trends in international mathematics and science study at fourth and eight grades. Boston: TIMSS \& PIRLS International Study Center, Lynch School of Education, Boston College.

Tutak, F. A, Bondy, E, \& Adams, T. (2011). Critical pedagogy for critical mathematics education; International Journal of Mathematics Education in Science and Technology, 42 (1), 65-74.

Willis, J. (2007). Foundations of qualitative research: Interpretive and critical approaches. Thousand Oaks, CA: Sage.

Wilson, K. \& Cooney, T. (2003). Mathematics teacher change and development: The role of belief. In G. C. Leder, E. Pehkonen, \&G. Törner (Eds.). Beliefs: A hidden variable in mathematics education? Dordrecht: Kluwer Academic Publishers. 